\title{
Children under 10 years of age were more affected by the 2018/19 influenza A(H1N1)pdm09 epidemic in Canada: possible cohort effect following the 2009 influenza pandemic
}

Danuta M Skowronski ${ }^{1,2}$, Siobhan Leir ${ }^{1}$, Gaston De Serres ${ }^{3,4,5}$, Michelle Murti6,7, James A Dickinson ${ }^{8}$, Anne-Luise Winter ${ }^{6}$, Romy Olsha6, Matthew A Croxen,10, Steven J Drews ${ }^{9,10}$, Hugues Charest ${ }^{3}$, Christine Martineau ${ }^{3}$, Suzana Sabaiduc ${ }^{1}$, Nathalie Bastien ${ }^{11}$, Yan $\mathrm{Li}^{11}$, Martin Petric ${ }^{2}$, Agatha Jassem ${ }^{1,2}$, Mel Krajden ${ }^{1,2}$, Jonathan B Gubbay ${ }^{6,7}$

1. British Columbia Centre for Disease Control, Vancouver, Canada

2. University of British Columbia, Vancouver, Canada

3. Institut National de Santé Publique du Québec, Quebec, Canada

4. Laval University, Quebec, Canada

5. Centre Hospitalier Universitaire de Québec, Quebec, Canada

6. Public Health Ontario, Toronto, Canada

7. University of Toronto, Toronto, Canada

8. University of Calgary, Calgary, Canada

9. Provincial Laboratory for Public Health, Edmonton, Canada

10. University of Alberta, Edmonton, Canada

11. National Microbiology Laboratory, Public Health Agency of Canada, Winnipeg, Canada

Correspondence: Danuta M Skowronski (danuta.skowronski@bccdc.ca)

Citation style for this article:

Skowronski Danuta M, Leir Siobhan, De Serres Gaston, Murti Michelle, Dickinson James A, Winter Anne-Luise, Olsha Romy, Croxen Matthew A, Drews Steven J, Charest Hugues, Martineau Christine, Sabaiduc Suzana, Bastien Nathalie, Li Yan, Petric Martin, Jassem Agatha, Krajden Mel, Gubbay Jonathan B. Children under 10 years of age were more affected by the $2018 / 19$ influenza $A\left(\mathrm{H}_{1} \mathrm{~N}_{1}\right)$ pdmog epidemic in Canada: possible cohort effect following the 2009 influenza pandemic. Euro Surveill. 2019;24(15):pii=1900104. https://doi.org/10.2807/1560-7917.ES.2019.24.15.1900104

Introduction: Findings from the community-based Canadian Sentinel Practitioner Surveillance Network (SPSN) suggest children were more affected by the 2018/19 influenza $A\left(\mathrm{H}_{1} \mathrm{~N}_{1}\right)$ pdmog epidemic. Aim: To compare the age distribution of $\mathrm{A}\left(\mathrm{H}_{1} \mathrm{~N}_{1}\right)$ pdmog cases in $2018 / 19$ to prior seasonal influenza epidemics in Canada. Methods: The age distribution of unvaccinated influenza $A\left(\mathrm{H}_{1} \mathrm{~N}_{1}\right)$ pdmog cases and test-negative controls were compared across $\mathrm{A}\left(\mathrm{H}_{1} \mathrm{~N}_{1}\right)$ pdmo9-dominant epidemics in 2018/19, 2015/16 and 2013/14 and with the general population of SPSN provinces. Similar comparisons were undertaken for influenza $A\left(\mathrm{H}_{3} \mathrm{~N}_{2}\right)$ dominant epidemics. Results: In 2018/19, more influenza $A\left(\mathrm{H}_{1} \mathrm{~N}_{1}\right)$ pdmo9 cases were under 10 years old than controls (29\% vs $16 \%$; $p$ < 0.001$)$. In particular, children aged 5-9 years comprised $14 \%$ of cases, greater than their contribution to controls $(4 \%)$ or the general population ( $5 \%$ ) and at least twice their contribution in 2015/16 (7\%; $p<0.001)$ or 2013/14 (5\%; $p<0.001)$. Conversely, children aged $10-19$ years (11\% of the population) were under-represented among $A\left(\mathrm{H}_{1} \mathrm{~N}_{1}\right)$ pdmog cases versus controls in 2018/19 (7\% vs $12 \%$; p < 0.001), 2015/16 (7\% vs 13\%; p < 0.001) and 2013/14 ( $9 \%$ vs $12 \% ; p=0.12$ ). Conclusion: Children under 10 years old contributed more to outpatient $A\left(\mathrm{H}_{1} \mathrm{~N}_{1}\right)$ pdmog medical visits in 2018/19 than prior seasonal epidemics in Canada. In 2018/19, all children under 10 years old were born after the $2009 \mathrm{~A}\left(\mathrm{H}_{1} \mathrm{~N}_{1}\right)$ pdmog pandemic and therefore lacked pandemic-induced immunity. In addition, more than half those born after 2009 now attend school (i.e. 5-9-year-olds), a socio-behavioural context that may enhance transmission and did not apply during prior $\mathrm{A}\left(\mathrm{H}_{1} \mathrm{~N}_{1}\right)$ pdmog epidemics.

\section{Introduction}

The 2018/19 seasonal influenza epidemic in the northern hemisphere has primarily been due to influenza $A$ viruses with fewer influenza B detections than usual [1-3]. In Canada, among influenza A viruses subtyped, the majority ( $>80 \%$ as at week 11 ) have been influenza $\mathrm{A}\left(\mathrm{H}_{1} \mathrm{~N}_{1}\right) p d m o 9$ [1]. Influenza $\mathrm{A}\left(\mathrm{H}_{1} \mathrm{~N}_{1}\right)$ pdmog viruses have also predominated elsewhere, including the United States (US) [2] and Europe [3,4], but with more variable contribution by influenza $A\left(\mathrm{H}_{3} \mathrm{~N}_{2}\right)$ subtype viruses. The last influenza $\mathrm{A}\left(\mathrm{H}_{1} \mathrm{~N}_{1}\right)$ pdmog-dominant epidemics in Canada occurred in 2013/14 [1,5] and 2015/16 [1,6]; $A\left(\mathrm{H}_{3} \mathrm{~N}_{2}\right)$ subtype viruses predominated in 2014/15 [1,7], 2016/17 [1,8] and 2017/18 [1,9].

The 2018/19 influenza $\mathrm{A}\left(\mathrm{H}_{1} \mathrm{~N}_{1}\right)$ pdmog epidemic in Canada began early in week 43, with paediatric hospitalisations above the seasonal norm as early as week 45 and national surveillance indicators showing the epidemic peak during week 522018 [1]. In a rapid 


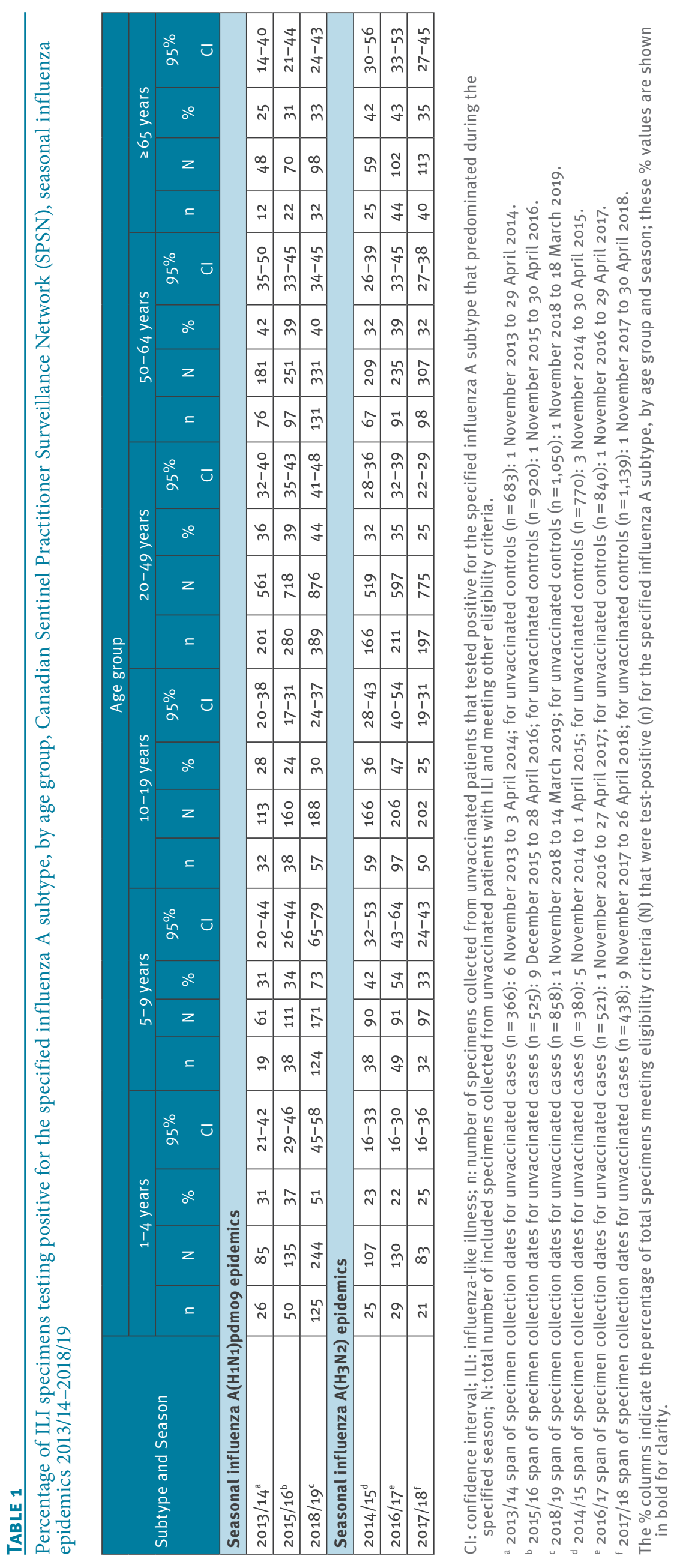


communication, published 24 January 2019, the community-based Canadian Sentinel Practitioner Surveillance Network (SPSN) reported early estimates of influenza vaccine effectiveness (VE) for the 2018/19 season [10]. Substantial VE against medically-attended outpatient influenza $A\left(\mathrm{H}_{1} \mathrm{~N}_{1}\right)$ pdmog illness was reported for all age groups and particularly for children. Vaccine protection against influenza $\mathrm{A}\left(\mathrm{H}_{1} \mathrm{~N}_{1}\right)$ pdmog was also subsequently reported among outpatients in the US [11], and Europe [12] and from Hong Kong among children requiring inpatient care [13].

The Canadian SPSN interim report, which captured cases as at week 2 2019, suggested that children aged less than 10 years were disproportionately affected by the 2018/19 influenza $A\left(\mathrm{H}_{1} \mathrm{~N}_{1}\right)$ pdmog epidemic [10]. Drawing on historical datasets of the Canadian SPSN since the 2013/14 seasonal influenza $A\left(\mathrm{H}_{1} \mathrm{~N}_{1}\right)$ pdmog epidemic, we examine and compare this age-related surveillance signal in more detail and inclusive of additional weeks spanning the tail end of the 2018/19 influenza $\mathrm{A}\left(\mathrm{H}_{1} \mathrm{~N}_{1}\right)$ pdmog epidemic.

\section{Methods}

Study participants and protocol

As described in prior SPSN publications [5-10], nasal/ nasopharyngeal specimens and epidemiological data were collected from patients presenting to communitybased sentinel practitioners in the four most populous provinces of Canada: Alberta, British Columbia, Ontario and Quebec. Eligible patients met a standardised case definition for influenza-like illness (ILI) consisting of acute onset of self-reported fever and cough and at least one other symptom including sore throat, myalgia, arthralgia or prostration [5-10]. The same ILI criteria applied each season and to all age groups, except that fever was not a requirement for elderly adults aged 65 years and older. All specimens were tested for influenza type and subtype by real-time RT-PCR assays at provincial public health laboratories; subtyping information was available for $\geq 95 \%$ of influenza $A$ viruses each season [5-10].

The current study is restricted to specimens collected from patients presenting within 7 days of ILI onset between 1 November and 30 April each seasonal influenza epidemic, except 2018/19 for which collection dates spanned from 1 November to specimens available as at 18 March 2019 [5-10] (Supplementary Figure $\mathrm{S} 1)$. Cases tested positive for the dominant influenza A subtype of a given season; controls tested negative for any influenza virus. Patients without available influenza A subtype information were excluded. To assess age distribution in the absence of vaccine effects, analyses were restricted to unvaccinated patientsaged 1 year or older. Unvaccinated patients were those selfreporting no influenza vaccine receipt (or as reported by their parent/guardian) in the season during which their specimen was collected.

\section{Ethical statement}

Although conducted as a surveillance initiative, the Canadian SPSN follows a study protocol that includes obtaining verbal consent from patients (or their parent/ guardian). During the study period the protocol was approved by the following ethics review committees in participating provinces: University of Calgary, Calgary, Alberta; University of British Columbia, Vancouver, British Columbia; University of Toronto (2013/142016/17), University Health Network (2013/14-2016/17), and Public Health Ontario (2017/18-2018/19), Toronto, Ontario; and Comité d'éthique de santé publique, Québec.

\section{Age-related analyses}

The age distribution of unvaccinated influenza $A\left(\mathrm{H}_{1} \mathrm{~N}_{1}\right)$ pdmog cases and unvaccinated controls in 2018/19 was primarily compared with prior influenza $A\left(\mathrm{H}_{1} \mathrm{~N}_{1}\right)$ pdmog-dominant seasonal epidemics (i.e. 2013/14 and 2015/16) [5,6]. Similar comparisons were undertaken for influenza $\mathrm{A}\left(\mathrm{H}_{3} \mathrm{~N}_{2}\right)$-dominant epidemics (i.e. 2014/15, 2016/17 and 2017/18) [7-9]. Age-related analyses and comparisons by season included:

(i) The percentage of ILI specimens testing positive for the specified influenza A subtype, by age group. Age groups included: children aged $1-4$ years; 5-9 years and $10-19$ years; and adults aged $20-49$ years; 50-64 years; and 65 years and older (elderly adults). Percentage positivity estimates were accompanied by $95 \%$ confidence intervals ( $\mathrm{Cls}$ ) and compared by chisquared analysis.

(ii) The percentage distribution of unvaccinated cases and controls by single year of age. Percentage histograms displayed the percentage of all cases (of the specified influenza A subtype) that belonged to a given age in years such that percentages sum $100 \%$ across the age range each season. The percentage distribution of influenza test-negative controls was superimposed upon the same season-specific plots to standardise for potential age-related sampling variation. The median age of cases and controls was compared within and across seasons by the Wilcoxon rank-sum test.

(iii) The percentage distribution of unvaccinated cases and controls by age group. Proportions were accompanied by $95 \% \mathrm{Cls}$ and compared by chi-squared analysis. Case/control distributions by age group were also compared with the general population of SPSN provinces (2018 data) (Supplementary Table S1) [14].

\section{Results}

Percentage positivity by age category

In Table 1, among specimens collected from unvaccinated patients with ILI, the age group with the highest influenza A test-positivity was children aged 5-9 years in $2018 / 19$ ( $73 \% \mathrm{~A}\left(\mathrm{H}_{1} \mathrm{~N}_{1}\right)$ pdmog positive). This positivity rate was not only significantly higher compared to the same age group during prior influenza $A\left(\mathrm{H}_{1} \mathrm{~N}_{1}\right)$ 


\section{FIGURE 1}

Percentage distribution of unvaccinated influenza $\mathrm{A}(\mathrm{H} 1 \mathrm{~N} 1) \mathrm{pdm} 09$ cases and controls by single year of age, Canadian Sentinel Practitioner Surveillance Network (SPSN), seasonal influenza A(H1N1)pdm09 epidemics 2013/14, 2015/16, 2018/19

\section{A. 2013/14 influenza epidemic ${ }^{a}$}

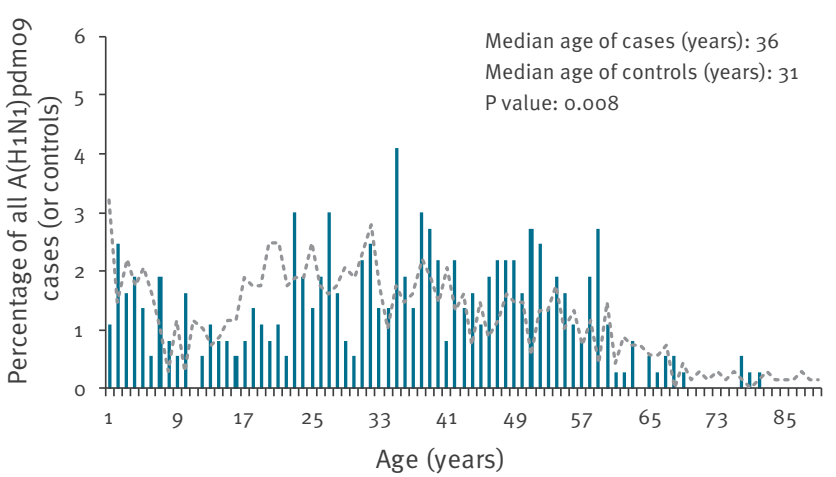

B. $2015 / 16$ influenza epidemic ${ }^{b}$

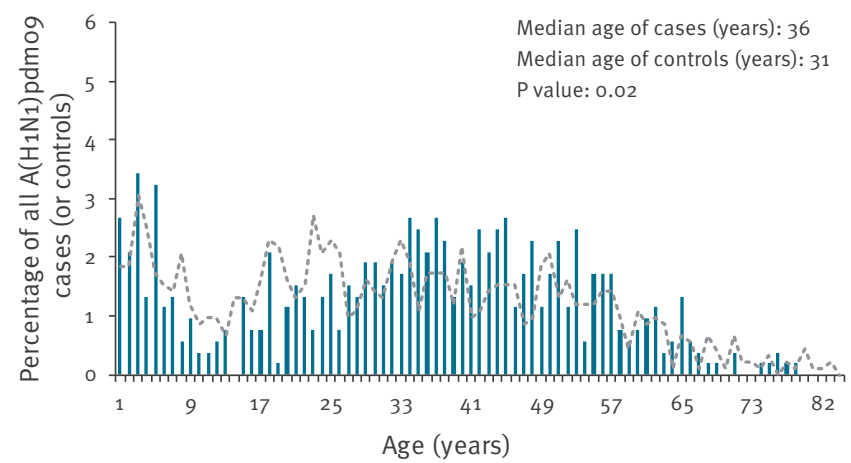

C. 2018/19 influenza epidemic ${ }^{c}$

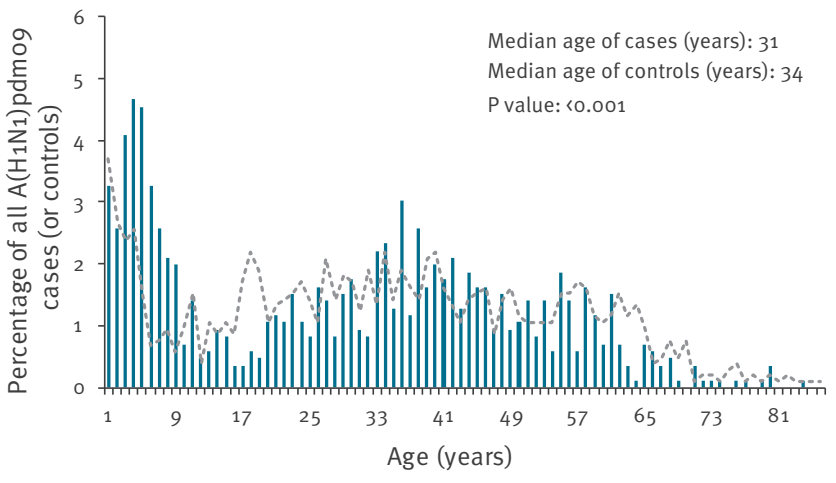

Influenza $A\left(\mathrm{H}_{1} \mathrm{~N}_{1}\right)$ pdmog cases

.... Influenza test-negative controls

a Span of specimen collection dates for unvaccinated cases $(n=366)$ : 6 November 2013 to 3 April 2014; for unvaccinated controls $(n=683)$ : 1 November 2013 to 29 April 2014

${ }^{b}$ Span of specimen collection dates for unvaccinated cases $(n=525)$ : 9 December 2015 to 28 April 2016; for unvaccinated controls $(n=920): 1$ November 2015 to 30 April 2016.

Span of specimen collection dates for unvaccinated cases $(n=858)$ : 1 November 2018 to 14 March 2019; for unvaccinated controls $(n=1050): 1$ November 2018 to 18 March 2019.

The percentage of all unvaccinated influenza $\mathrm{A}\left(\mathrm{H}_{1} \mathrm{~N}_{1}\right)$ pdmog cases belonging to a given single year of age is displayed as a blue bar; the same information for unvaccinated influenza test-negative controls is superimposed as a dotted line to indicate the sampling distribution by age for comparison purposes. The $p$ values displayed are pdmog epidemics in 2015/16 (34\%; p< 0.001$)$ and $2013 / 14$ (31\%; $p<0.001)$, but it was also significantly higher compared to any other age group in any other seasonal epidemic assessed (all p values $<0.005$ ).

Higher influenza $A\left(\mathrm{H}_{1} \mathrm{~N}_{1}\right)$ pdmog test-positivity was also observed among children aged $1-4$ years in $2018 / 19$ compared to $2015 / 16$ and $2013 / 14$ ( $51 \%$ vs $37 \% ; p=0.008$ and $31 \% ; p=0.001$, respectively) and among adults $20-49$ years old ( $44 \%$ vs $39 \% ; p=0.03$ and $36 \% ; p=0.001$, respectively), but these differences were less striking. Other age groups showed no significant differences across these seasons.

The next highest percentage influenza A positivity (54\%) also involved children aged $5-9$ years but during the influenza $\mathrm{A}\left(\mathrm{H}_{3} \mathrm{~N}_{2}\right)$ epidemic in $2016 / 17(p=0.002$ compared with 2018/19). Children aged $10-19$ years also had higher influenza $\mathrm{A}\left(\mathrm{H}_{3} \mathrm{~N}_{2}\right)$ positivity rates in $2016 / 17(47 \%)$, greater than for any other season for that age group (36\% in 2014/15 ( $p=0.03) ; p<0.005$ any other seasons' comparisons). Among those aged 65 years and older, influenza test-positivity was also generally higher during $\mathrm{A}\left(\mathrm{H}_{3} \mathrm{~N}_{2}\right)$ vs $\mathrm{A}\left(\mathrm{H}_{1} \mathrm{~N}_{1}\right)$ pdmog epidemics, marginally significant in comparing positivity across combined $\mathrm{A}\left(\mathrm{H}_{3} \mathrm{~N}_{2}\right)$ vs $\mathrm{A}\left(\mathrm{H}_{1} \mathrm{~N}_{1}\right)$ pdmog epidemics ( $40 \%$ vs $31 \% ; p=0.03)$ and between $2016 / 17$ vs $2013 / 14$ ( $43 \%$ vs $25 \% ; p=0.03$.

\section{Percentage distribution by age in years}

As shown in Figure 1, the distribution of unvaccinated influenza $\mathrm{A}\left(\mathrm{H}_{1} \mathrm{~N}_{1}\right)$ pdmog cases was more highly skewed towards children aged 1-9-years in 2018/19 but with a relative paucity of cases aged $10-19$ years during each seasonal $A\left(\mathrm{H}_{1} \mathrm{~N}_{1}\right)$ pdmog epidemic including 2018/19. Shift toward greater involvement of children less than 10 years old was also evident in 2015/16 compared with $2013 / 14$, but became more pronounced in 2018/19. In particular, children between the ages of 3-5 years each comprised the greatest proportion ( $4 \%$ or more) of $A\left(\mathrm{H}_{1} \mathrm{~N}_{1}\right)$ pdmog cases in 2018/19. However, children between the ages of $6-9$ years were also more substantially affected, with each single year of age in that grouping newly comprising $2 \%$ or more of $\mathrm{A}\left(\mathrm{H}_{1} \mathrm{~N}_{1}\right)$ pdmog cases in 2018/19 whereas they had each comprised less than $2 \%$ of cases in $2015 / 16$ and $2013 / 14$.

Comparing the age distributions of cases and controls across seasons (not shown) the median age of $A\left(\mathrm{H}_{1} \mathrm{~N}_{1}\right)$ pdmo9 cases in 2018/19 (31 years) was lower than for cases in 2015/16 and 2013/14 (both 36 years; $p<0.001)$; whereas, the median age of controls did not significantly differ (or was higher) in 2018/19 (34 years) compared to controls in 2015/16 and 2013/14 (both 31 years; $p=0.04$ and 0.11 , respectively). Comparing the age distributions of cases versus controls within the same seasons (as shown in Figure 1), the median age of cases in 2018/19 was younger than controls (31 vs 34 years; $p<0.001$ ) whereas cases were older than controls in both 2015/16 and 2013/14 (36 vs 31 years both seasons; $p<0.02$ and $<0.01$, respectively). 


\section{FIGURE 2}

Percentage distribution of unvaccinated influenza $\mathrm{A}(\mathrm{H} 3 \mathrm{~N} 2)$ cases and controls by single year of age, Canadian Sentinel Practitioner Surveillance Network (SPSN), seasonal influenza A(H3N2) epidemics 2014/15, 2016/17, 2017/18

\section{A. 2014/15 influenza epidemic ${ }^{a}$}

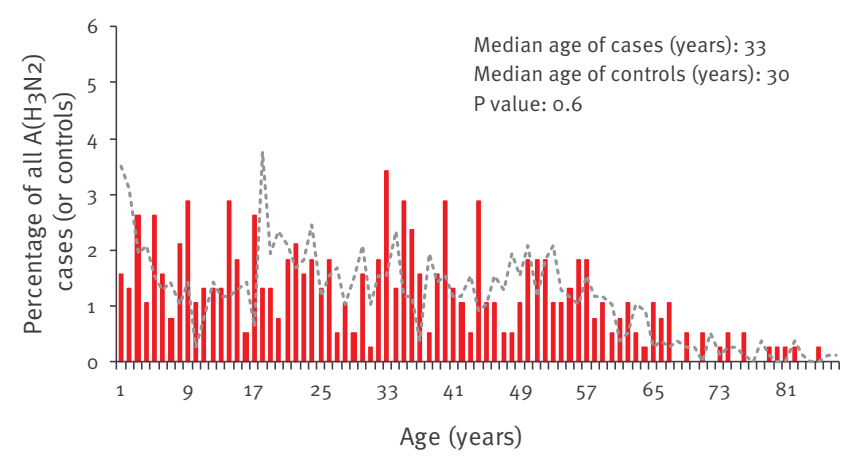

B. 2016/17 influenza epidemic ${ }^{\text {b }}$

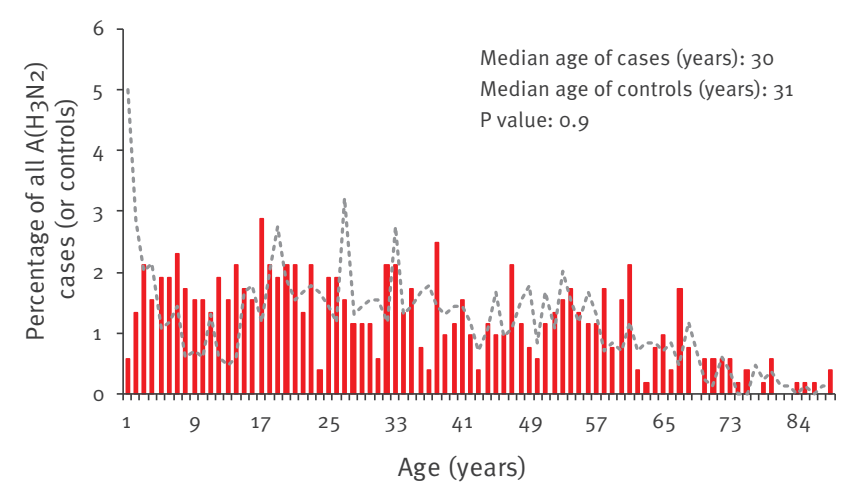

C. 2017/18 influenza epidemic ${ }^{c}$

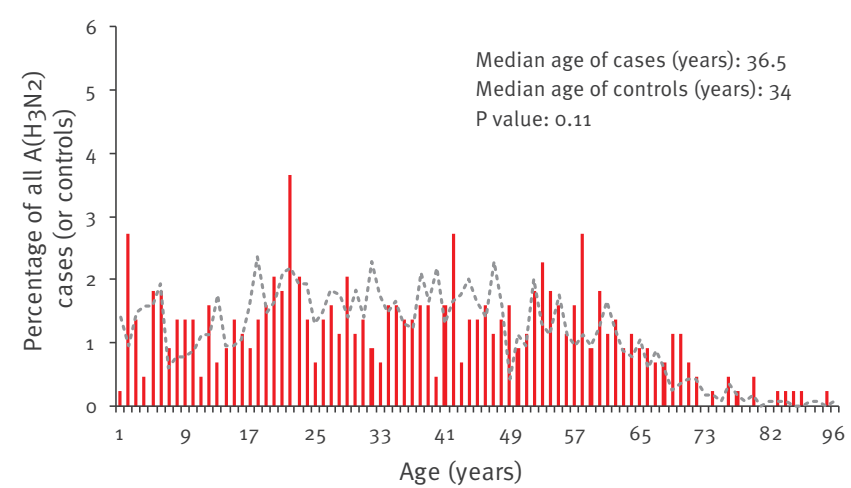

Influenza $A\left(\mathrm{H}_{3} \mathrm{~N}_{2}\right)$ cases

.... Influenza test-negative controls

a Span of specimen collection dates for unvaccinated cases $(n=380): 5$ November 2014 to 1 April 2015; for unvaccinated controls $(n=770): 3$ November 2014 to 30 April 2015.

${ }^{\mathrm{b}}$ Span of specimen collection dates for unvaccinated cases $(n=521): 1$ November 2016 to 27 April 2017; for unvaccinated controls $(n=840)$ : 1 November 2016 to 29 April 2017.

Span of specimen collection dates for unvaccinated cases $(n=438)$ : 9 November 2017 to 26 April 2018; for unvaccinated controls $(n=1,139)$ : 1 November 2017 to 30 April 2018.

The percentage of all unvaccinated influenza $\mathrm{A}\left(\mathrm{H}_{3} \mathrm{~N}_{2}\right)$ cases belonging to a given single year of age is displayed as a red bar; the same information for unvaccinated influe year of age is displayed as a red bar; the same infort lo sampling distribution by age for comparison purposes. The p values displayed are for the comparison between median ages of cases and con or the comparison between median ages of cases and controls within the same season.
Influenza $\mathrm{A}\left(\mathrm{H}_{3} \mathrm{~N}_{2}\right)$ cases were more evenly distributed across the age range (Figure 2). In 2017/18, the median age of influenza $A\left(\mathrm{H}_{3} \mathrm{~N}_{2}\right)$ cases was 36.5 years, greater than in 2016/17 (30 years; $p=0.004$ ) and 2014/15 (33 years; $p=0.003$ ). However, a similar pattern was observed in controls, with median age of 34 years in $2017 / 18$ that was greater than in 2016/17 (31 years; $p=0.01$ ) and 2014/15 (30 years; $p=0.001$ ).

\section{Percentage distribution by age category}

In 2018/19, children less than 10 years old comprised a greater proportion of influenza $\mathrm{A}\left(\mathrm{H}_{1} \mathrm{~N}_{1}\right)$ pdmog cases than controls ( $29 \%$ vs $16 \%$; $p<0.001)$, greater also than their share of the general population of SPSN provinces $(10 \%)$ or their contribution to cases in 2015/16 (17\%; $\mathrm{p}<0.001$ ) or $2013 / 14$ (12\%; $\mathrm{p}<0.001)$. (Figure 3, Table 2 and Supplementary Table S1) [14].

The percentage of all unvaccinated cases of the specified influenza A subtype and all unvaccinated controls within a given season that belonged to the specified age group are displayed. The percentage that were children aged $1-4$ years is shown in panel $A$, children 5-9 years in panel $B$, children $10-19$ years in panel $C$ and adults 65 years and older in panel D. More detailed information, including case distributions among other adult categories, is provided in Table 2.

Blue bars represent $A\left(\mathrm{H}_{1} \mathrm{~N}_{1}\right)$ pdmog case distributions during influenza $A\left(\mathrm{H}_{1} \mathrm{~N}_{1}\right)$ pdmog epidemic seasons (2013/14, 2015/16 and 2018/19), red bars represent $A\left(\mathrm{H}_{3} \mathrm{~N}_{2}\right)$ case distributions during influenza $A\left(\mathrm{H}_{3} \mathrm{~N}_{2}\right)$ epidemic seasons $(2014 / 15,2016 / 17$ and 2017/18) and grey bars represent influenza test-negative controls. Associated case/control counts are available in Table 2.

The proportion of $\mathrm{A}\left(\mathrm{H}_{1} \mathrm{~N}_{1}\right)$ pdmog cases that were children aged $1-4$ years increased from $7 \%$ in $2013 / 14$ and $10 \%$ in $2015 / 16$ to $15 \%$ in $2018 / 19$ ( $p<0.001$ and $<0.01$ comparing both prior epidemics to $2018 / 19$, respectively) (Figure 3, Table 2). However, this may reflect increased sampling from that age group, given that their control contribution also increased from $9 \%$ in both $2013 / 14$ and $2015 / 16$ to $11 \%$ in $2018 / 19$ ( $p=0.07$ and 0.13 , respectively). Overall, the proportion of cases that were children aged $1-4$ years in 2018/19 was marginally greater among cases than among controls (15\% vs $11 \% ; p=0.04$ ) with both exceeding the proportion aged $1-4$ years in the general population of SPSN provinces (4\%) (Supplementary Table S1) [14].

The proportion of $\mathrm{A}\left(\mathrm{H}_{1} \mathrm{~N}_{1}\right)$ pdmog cases that were children aged 5-9 years also increased from 5\% in 2013/14 and $7 \%$ in $2015 / 16$ to $14 \%$ in $2018 / 19$ ( $p<0.001$ comparing both prior epidemics to 2018/19) (Figure 3, Table 2). However, unlike children aged $1-4$ years, this pattern was not evident in their control contribution in 2018/19 ( $4 \%)$, with there instead being a slight decline from $2013 / 14$ (6\%, $p=0.12)$ and 2015/16 (8\%; $p<0.01)$. The case contribution by children aged 5-9 years in 2018/19 was thus disproportionate to their control contribution 


\section{FIGURE 3}

Percentage distribution of unvaccinated cases and controls, paediatric and elderly adult age groups, Canadian Sentinel Practitioner Surveillance Network (SPSN), seasonal influenza epidemics 2013/14-2018/19

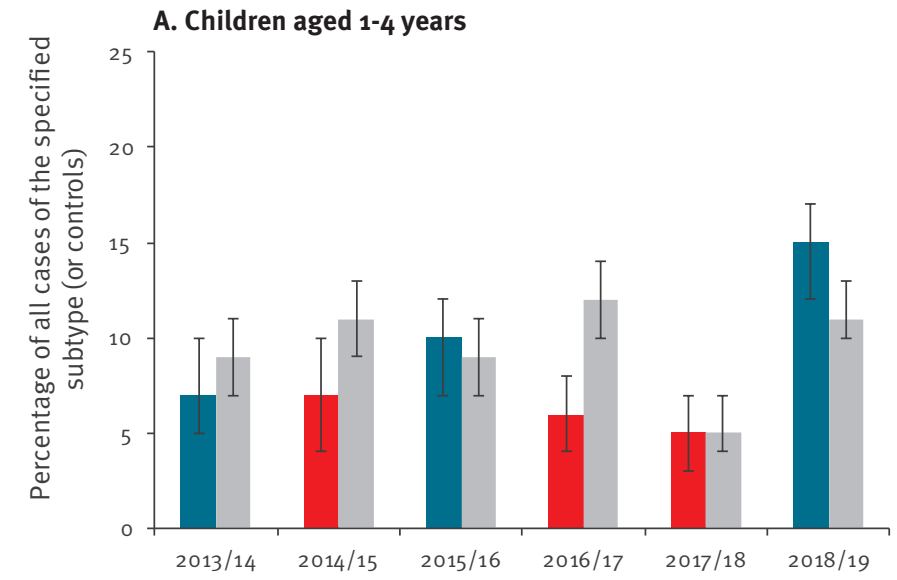

C. Children aged 10-19 years

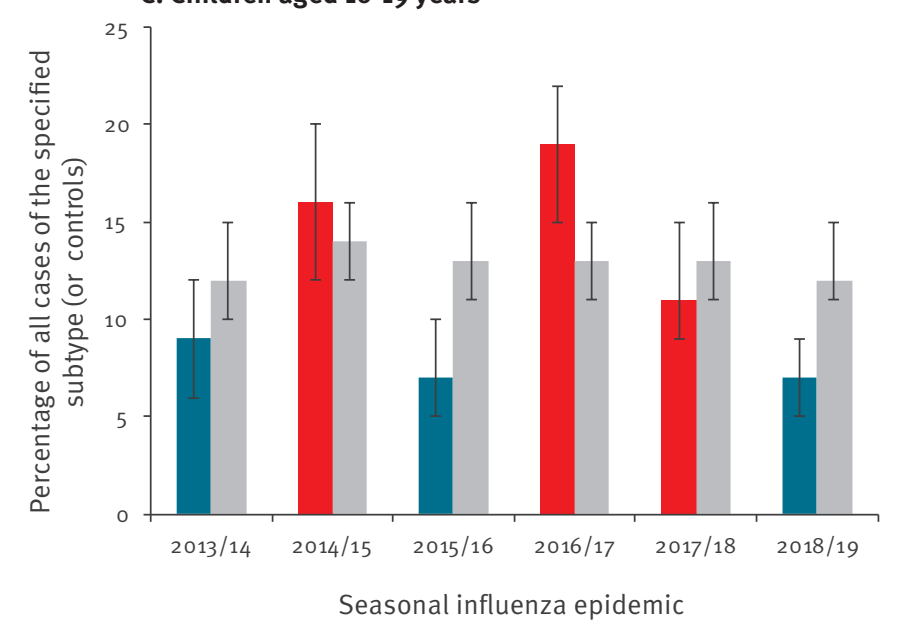

B. Children aged 5-9 years

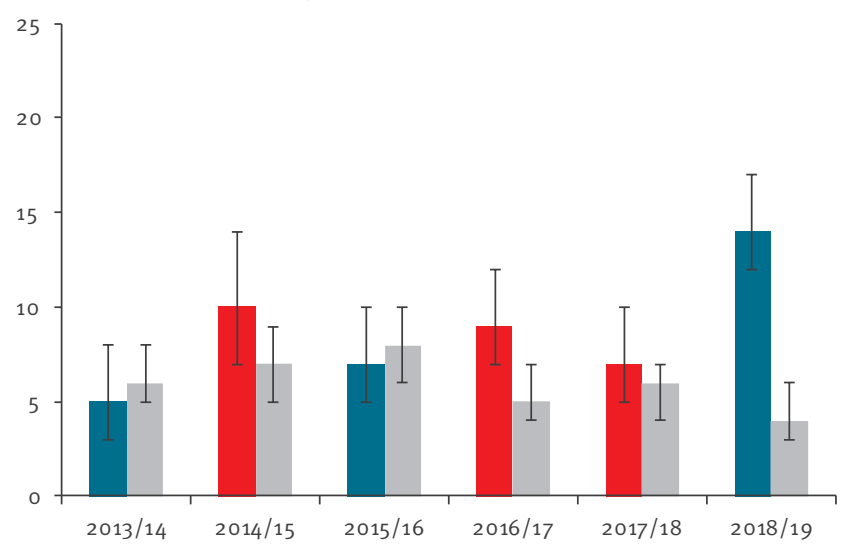

D. Elderly adults aged 65 years or older

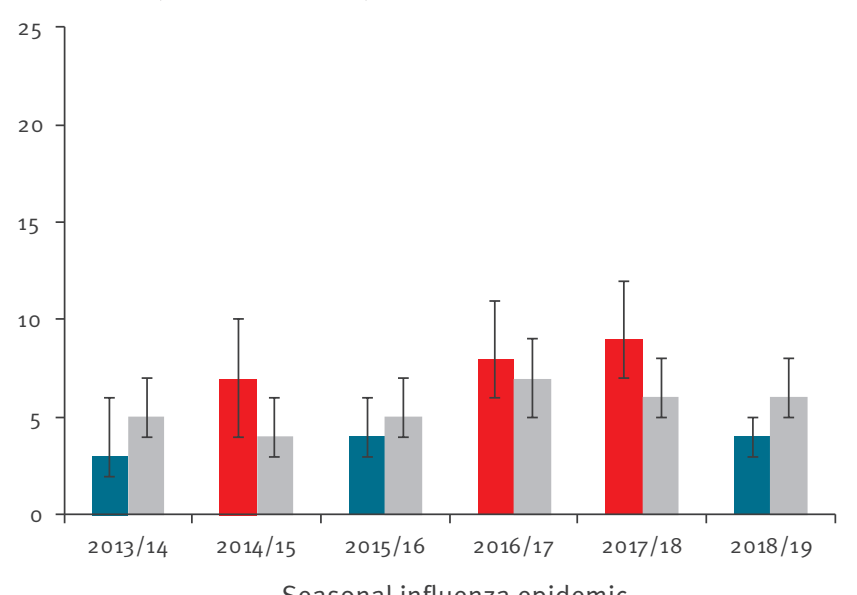

Seasonal influenza epidemic

Influenza $\mathrm{A}\left(\mathrm{H}_{1} \mathrm{~N}_{1}\right)$ pdmog, \% distribution

Influenza $\mathrm{A}\left(\mathrm{H}_{3} \mathrm{~N}_{2}\right)$, \% distribution

Influenza test-negative controls, \% distribution

The percentage of all unvaccinated cases of the specified influenza A subtype and all unvaccinated controls within a given season that belonged to the specified age group are displayed. The percentage that were children aged $1-4$ years is shown in panel $A$, children $5-9$ years in panel B, children 10-19 years in panel C and adults 65 years and older in panel D. More detailed information, including case distributions among other adult categories, is provided in Table 2.

Blue bars represent $A\left(\mathrm{H}_{1} \mathrm{~N}_{1}\right)$ pdmog case distributions during influenza $A\left(\mathrm{H}_{1} \mathrm{~N}_{1}\right)$ pdmog epidemic seasons (2013/14, 2015/16 and 2018/19), red bars represent $A\left(\mathrm{H}_{3} \mathrm{~N}_{2}\right)$ case distributions during influenza $A\left(\mathrm{H}_{3} \mathrm{~N}_{2}\right)$ epidemic seasons $(2014 / 15,2016 / 17$ and $2017 / 18)$ and grey bars represent influenza test-negative controls. Associated case/control counts are available in Table 2.

( $14 \%$ vs $4 \% ; p<0.001)$, the latter otherwise approximating their share of the general population (5\%) (Supplementary Table S1) [14]. The influenza $A\left(\mathrm{H}_{1} \mathrm{~N}_{1}\right)$ pdmo9 case contribution by children aged 5-9 years in $2018 / 19$ was also greater than their $\mathrm{A}\left(\mathrm{H}_{3} \mathrm{~N}_{2}\right)$ case contribution during prior $\mathrm{A}\left(\mathrm{H}_{3} \mathrm{~N}_{2}\right)$ epidemics (ranging 7-10\%; $p<0.05$ each comparison) (Figure 3, Table 2).

The case contribution by other age groups in 2018/19 was more comparable to, or below that of, their contribution to controls or to cases and controls during prior seasons (Table 2). In particular, children aged 10-19 years (comprising $11 \%$ of the general population) were under-represented among $\mathrm{A}\left(\mathrm{H}_{1} \mathrm{~N}_{1}\right)$ pdmog cases relative to controls in 2018/19 ( $7 \%$ vs $12 \%$; $p<0.001$ ), as well as 2015/16 (7\% vs 13\%; $p<0.001)$ and to a lesser extent in 2013/14 ( $9 \%$ vs $12 \% ; p=0.12$ ) (Figure 3, Table 2, Supplementary Table S1) [14]. Children 10-19 years old contributed fewer cases across combined $A\left(\mathrm{H}_{1} \mathrm{~N}_{1}\right)$ pdmog epidemics (7\%) than combined $A\left(\mathrm{H}_{3} \mathrm{~N}_{2}\right)$ epidemics ( $15 \%$; $p<0.001)$ or relative to controls combined (13\% and $13 \%$, respectively; $p<0.001$ both comparisons). Adults aged 65 years and older also contributed less during influenza $A\left(\mathrm{H}_{1} \mathrm{~N}_{1}\right)$ pdmog epidemics combined (4\%) compared with $\mathrm{A}\left(\mathrm{H}_{3} \mathrm{~N}_{2}\right)$ epidemics combined $(8 \% ; p<0.001)$, while comprising the same 
TABLE 2

Percentage distribution of unvaccinated cases and controls by age group, Canadian Sentinel Practitioner Surveillance Network (SPSN), Canada, seasonal influenza epidemics 2013/14-2018/19

\begin{tabular}{|c|c|c|c|c|c|c|}
\hline \multirow[b]{2}{*}{ Age group (years) } & \multicolumn{3}{|c|}{ Cases } & \multicolumn{3}{|c|}{ Controls } \\
\hline & $\mathrm{n}$ & $\%$ & $95 \% \mathrm{Cl}$ & $\mathrm{n}$ & $\%$ & $95 \% \mathrm{Cl}$ \\
\hline \multicolumn{7}{|c|}{ Influenza $\mathrm{A}\left(\mathrm{H}_{1} \mathrm{~N}_{1}\right)$ pdmog epidemics } \\
\hline \multicolumn{7}{|l|}{ 2013/14 } \\
\hline Total & \multicolumn{3}{|c|}{366} & \multicolumn{3}{|c|}{683} \\
\hline $1-4$ & 26 & 7 & $5-10$ & 59 & 9 & 7-11 \\
\hline $5-9$ & 19 & 5 & $3-8$ & 42 & 6 & $5-8$ \\
\hline $10-19$ & 32 & 9 & $6-12$ & 81 & 12 & $10-15$ \\
\hline $20-49$ & 201 & 55 & $50-60$ & 360 & 53 & $49-57$ \\
\hline $50-64$ & 76 & 21 & $17-25$ & 105 & 15 & $13-18$ \\
\hline$\geq 65$ & 12 & 3 & $2-6$ & 36 & 5 & $4-7$ \\
\hline \multicolumn{7}{|l|}{$2015 / 16$} \\
\hline Total & \multicolumn{3}{|c|}{525} & \multicolumn{3}{|c|}{920} \\
\hline $1-4$ & 50 & 10 & $7-12$ & 85 & 9 & 7-11 \\
\hline $5-9$ & 38 & 7 & $5-10$ & 73 & 8 & $6-10$ \\
\hline $10-19$ & 38 & 7 & $5-10$ & 122 & 13 & $11-16$ \\
\hline $20-49$ & 280 & 53 & $49-58$ & 438 & 48 & $44-51$ \\
\hline $50-64$ & 97 & 18 & $15-22$ & 154 & 17 & $14-19$ \\
\hline$\geq 65$ & 22 & 4 & $3-6$ & 48 & 5 & $4-7$ \\
\hline \multicolumn{7}{|l|}{$2018 / 19$} \\
\hline Total & \multicolumn{3}{|c|}{858} & \multicolumn{3}{|c|}{1050} \\
\hline $1-4$ & 125 & 15 & $12-17$ & 119 & 11 & $10-13$ \\
\hline $5-9$ & 124 & 14 & $12-17$ & 47 & 4 & $3-6$ \\
\hline $10-19$ & 57 & 7 & $5-9$ & 131 & 12 & $11-15$ \\
\hline $20-49$ & 389 & 45 & $42-49$ & 487 & 46 & 43-50 \\
\hline $50-64$ & 131 & 15 & $13-18$ & 200 & 19 & $17-22$ \\
\hline$\geq 65$ & 32 & 4 & 3-5 & 66 & 6 & $5-8$ \\
\hline \multicolumn{7}{|c|}{ Influenza $\mathrm{A}\left(\mathrm{H}_{3} \mathrm{~N}_{2}\right)$ epidemics } \\
\hline \multicolumn{7}{|l|}{ 2014/15 } \\
\hline Total & \multicolumn{3}{|c|}{380} & \multicolumn{3}{|c|}{770} \\
\hline $1-4$ & 25 & 7 & 4-10 & 82 & 11 & $9-13$ \\
\hline $5-9$ & 38 & 10 & 7-14 & 52 & 7 & $5-9$ \\
\hline $10-19$ & 59 & 16 & $12-20$ & 107 & 14 & $12-17$ \\
\hline $20-49$ & 166 & 44 & $39-49$ & 353 & 46 & $42-49$ \\
\hline $50-64$ & 67 & 18 & $14-22$ & 142 & 18 & $16-21$ \\
\hline$\geq 65$ & 25 & 7 & 4-10 & 34 & 4 & $3-6$ \\
\hline \multicolumn{7}{|l|}{$2016 / 17$} \\
\hline Total & \multicolumn{3}{|c|}{521} & \multicolumn{3}{|c|}{840} \\
\hline $1-4$ & 29 & 6 & 4-8 & 101 & 12 & $10-14$ \\
\hline $5-9$ & 49 & 9 & 7-12 & 42 & 5 & 4-7 \\
\hline $10-19$ & 97 & 19 & $15-22$ & 109 & 13 & $11-15$ \\
\hline $20-49$ & 211 & 40 & $36-45$ & 386 & 46 & $43-49$ \\
\hline $50-64$ & 91 & 17 & $14-21$ & 144 & 17 & $15-20$ \\
\hline$\geq 65$ & 44 & 8 & $6-11$ & 58 & 7 & $5-9$ \\
\hline $2017 / 18$ & & & & & & \\
\hline Total & & & & & & \\
\hline $1-4$ & 21 & 5 & $3-7$ & 62 & 5 & $4-7$ \\
\hline $5-9$ & 32 & 7 & $5-10$ & 65 & 6 & $4-7$ \\
\hline $10-19$ & 50 & 11 & 9-15 & 152 & 13 & $11-16$ \\
\hline $20-49$ & 197 & 45 & $40-50$ & 578 & 51 & $48-54$ \\
\hline $50-64$ & 98 & 22 & $19-27$ & 209 & 18 & $16-21$ \\
\hline$\geq 65$ & 40 & 9 & $7-12$ & 73 & 6 & $5-8$ \\
\hline
\end{tabular}

$\mathrm{Cl}$ : confidence interval.

The percentage (\%) columns indicate the percentage of total influenza A cases of the specified subtype (or influenza test-negative controls) by seasonal influenza epidemic that belong to the specified age category; these $\%$ values are shown in bold for clarity. overall proportion of controls ( $6 \%$ combined $A\left(\mathrm{H}_{1} \mathrm{~N}_{1}\right)$ pdmog epidemics and 6\% combined $\mathrm{A}\left(\mathrm{H}_{3} \mathrm{~N}_{2}\right)$ epidemics). Each season, however, adults aged 65 years and older were under-represented among outpatient ILI visits relative to their share of the general population (17\%) (Supplementary Table S1) [14].

\section{Discussion}

Findings across successive seasons of influenza monitoring by the Canadian SPSN show greater involvement of children aged less than 10 years among outpatient medical visits during the 2018/19 influenza $A\left(\mathrm{H}_{1} \mathrm{~N}_{1}\right)$ pdmog epidemic. In particular, children aged 5-9 years were disproportionately affected, comprising $14 \%$ of all cases in 2018/19 which is at least twice that of their contribution during prior $\mathrm{A}\left(\mathrm{H}_{1} \mathrm{~N}_{1}\right)$ pdmog epidemics in 2013/14 (5\%) and 2015/16 (7\%). Over-sampling of children 5-9 years old during the 2018/19 season is unlikely to explain these observations given their contribution to influenza test-negative controls (4\%), commensurate with the general population of SPSN provinces (5\%) [14].

Moving cohort effects can be followed in relation to major immunological priming events, such as pandemics, to anticipate relative age-related susceptibility during subsequent epidemics. In that regard, our observations in 2018/19 may have an immunoepidemiological explanation. Infection rates during the 2009 pandemic were very high, especially in children (ca 47\% among those aged 5-19 years), resulting in high levels of infection-induced immunity $[15,16]$. Subsequent seasonal epidemics will have also contributed to population immunity, although influenza infection rates outside of pandemics are generally much lower [17]. Correlating that understanding with our agerelated observations, in 2013/14 children aged less than 5 years lacked 2009 pandemic-induced immunity as they were not yet born in 2009; in Canada, this was evident in the lowest sero-protection rates against $\mathrm{A}\left(\mathrm{H}_{1} \mathrm{~N}_{1}\right)$ pdmog measured in that age group pre-season in 2013 [16]. Two years later, in 2015/16, this moving cohort of children lacking 2009 pandemic exposure included all children aged 7 years or less; in addition, children under 2 years of age would have missed the opportunity to acquire (or boost) immunity during the $2013 / 14$ influenza epidemic. Finally, in 2018/19, those lacking 2009 pandemic-induced immunity included the expanded group of under 10-year-olds; additionally, children under 5 years lacked exposure to the 2013/14 epidemic and children under 3 years lacked exposure to the $2015 / 16$ epidemic. Overall in $2018 / 19$, compared to prior seasonal influenza epidemics, a greater proportion of children less than 10 years old would have lacked immunity to $\mathrm{A}\left(\mathrm{H}_{1} \mathrm{~N}_{1}\right)$ pdmog viruses.

Furthermore, in 2018/19, more than half those born after the 2009 pandemic now attend school (i.e. aged 5-9 years) - a context that did not apply in previous $\mathrm{A}\left(\mathrm{H}_{1} \mathrm{~N}_{1}\right)$ pdmog seasonal epidemics and may have enhanced transmission. School children are efficient 
propagators of infections transmitted by the respiratory or close contact route [18-20]. Facilitating this transmission potential, the mean number of daily contacts increases gradually by age in childhood, peaking between ages $10-19$ years $[18,19]$. Consistent with those epidemiological circumstances, surveillance observations showed that children aged 5-19 years (i.e. school age) contributed disproportionately during influenza $A\left(\mathrm{H}_{3} \mathrm{~N}_{2}\right)$ epidemics relative to controls. Younger school age children 5-9 years old also contributed disproportionately during the 2018/19 $\mathrm{A}\left(\mathrm{H}_{1} \mathrm{~N}_{1}\right)$ pdmog epidemic, whereas older school age children 10-19 years old were under-represented during all seasonal $A\left(\mathrm{H}_{1} \mathrm{~N}_{1}\right)$ pdmog epidemics. We hypothesise that children aged 5-9 years were disproportionately affected in 2018/19 because for the first time, that wellconnected group was fully comprised of children lacking the 2009 pandemic experience. Conversely, older school age children (10-19 years) each season (including 2018/19) were comprised of those who had previously lived through the 2009 pandemic, with greater likelihood of $A\left(\mathrm{H}_{1} \mathrm{~N}_{1}\right)$ pdmog immunity on that basis.

Most contacts of children are of a similar age, but also include siblings and parents and these contacts tend to be of long duration $[18,19]$. The combination of greater susceptibility and richer contact networks among school-aged children 5-9 years old in 2018/19 may have amplified spread beyond their immediate peers. This may be evident in the higher percentage of influenza test-positive specimens also found among younger children and adults in 2018/19. It may also be evident in the bimodal age distribution of $A\left(\mathrm{H}_{1} \mathrm{~N}_{1}\right)$ pdmog cases with a secondary peak among adults. However, this bimodal age pattern is not evident in the $\mathrm{A}\left(\mathrm{H}_{3} \mathrm{~N}_{2}\right)$ case distribution, despite the disproportionate involvement of school-aged children during those epidemics also. The appearance of a bimodal peak for $\mathrm{A}\left(\mathrm{H}_{1} \mathrm{~N}_{1}\right)$ pdmog cases may instead reflect the relative paucity of cases among those who acquired immunity as children during the $\mathrm{A}\left(\mathrm{H}_{1} \mathrm{~N}_{1}\right)$ pdmog pandemic (e.g. those 20 years or younger at the time). It is unknown whether the $\mathrm{A}\left(\mathrm{H}_{1} \mathrm{~N}_{1}\right)$ pdmog attack rates in $2018 / 19$ will prove sufficient to arrest or substantially attenuate the moving cohort of paediatric susceptibility we describe following the 2009 influenza pandemic. If not, that susceptibility may next extend to include those older than 10 years who have, on average, the greatest number of effective contacts $[18,19]$, a potentially precarious combination for future $\mathrm{A}\left(\mathrm{H}_{1} \mathrm{~N}_{1}\right)$ pdmog epidemics.

Immunological cohort effects may also be expressed in more complex ways across the life span. Priming to the particular influenza viruses of first childhood exposure may leave lasting immunological imprints that can negatively or positively affect responses during subsequent influenza virus encounters [21-23]. Such historic priming effects were hypothesised to explain greater $\mathrm{A}\left(\mathrm{H}_{1} \mathrm{~N}_{1}\right)$ pdmog susceptibility among non-elderly adults during recent seasonal epidemics $[6,21]$. Conversely, immunity generated by early childhood exposure to closely-related ancestral viruses has been hypothesized to explain lower $\mathrm{A}\left(\mathrm{H}_{1} \mathrm{~N}_{1}\right)$ pdmog susceptibility decades later among elderly adults during the $\mathrm{A}\left(\mathrm{H}_{1} \mathrm{~N}_{1}\right)$ pdmog pandemic [23] and subsequent seasonal $\mathrm{A}\left(\mathrm{H}_{1} \mathrm{~N}_{1}\right)$ pdmog epidemics. The timeline for persistence of this pre-existing protection against $\mathrm{A}\left(\mathrm{H}_{1} \mathrm{~N}_{1}\right)$ pdmog viruses in elderly adult cohorts requires monitoring. In the meantime, reduced susceptibility to influenza $\mathrm{A}\left(\mathrm{H}_{1} \mathrm{~N}_{1}\right)$ pdmog subtype viruses among elderly adults may be negatively correlated with their greater susceptibility to influenza $A\left(\mathrm{H}_{3} \mathrm{~N}_{2}\right)$ subtype viruses [24,25], an ecological association that warrants more definitive evaluation.

The SPSN places no age restrictions on influenza testing and includes patients meeting the same ILI testing indication. No relevant system changes were introduced during the study period to account for the age-related shift in influenza $A\left(\mathrm{H}_{1} \mathrm{~N}_{1}\right)$ pdmog cases we observed. Although particular diagnostic assays varied, all test sites are accredited clinical and public health diagnostic and reference laboratories subject to regular proficiency testing programs, conducted at least thrice annually. Either way, assay changes were not applied differentially by age to SPSN specimens. Although children may shed more virus and/or for longer periods $[26,27]$, this is not expected to differ by season and all included specimens were collected within 7 days of ILI onset with the same median interval from ILI onset to specimen collection (3 days) in 2018/19 compared with $2015 / 16$ and $2013 / 14$, overall, stratified by cases/controls and restricted to children 1-9 years of age (data not shown).

To assess age distribution in the absence of vaccine effects, which vary by age, subtype and season $[5-10,28]$, we restricted the analysis to patients who self-reported being unvaccinated. Although we did not account for prior vaccination history, this is highly correlated with current season's vaccination status [5-10]. In sensitivity analyses, we included patients who self-reported influenza vaccination, and the same age-related patterns were observed (Supplementary Figure S2 and Supplementary Figure S3). This is not unexpected since analyses overall remain driven by the majority of SPSN participants (about two-thirds) [5-10], who did not receive influenza vaccine, similar to the profile in the general population [29]. Inclusive of vaccinated participants, the median ages of both cases and controls were older in all seasons but this is also not unexpected given greater vaccine coverage among elderly adults and those with high-risk conditions targeted by the annual influenza vaccination campaign.

Less than $25 \%$ of SPSN participants aged $1-9$ years received influenza vaccine each season [5-10], including 2018/19 (data not shown). Between 2014/15 and $2016 / 17$, about half of vaccinated SPSN participants aged 1-9 years for whom the formulation was known were reported to have received live attenuated influenza vaccine (LAIV). However, following changes to 
LAIV recommendations in the US and Canada [30-32], this proportionate LAIV use fell below $20 \%$ among vaccinated participants aged 1-9 years in 2017/18 and $2018 / 19$. Overall, LAIV comprised less than $5 \%$ of total influenza vaccine doses distributed by the publiclyfunded programme across SPSN provinces in 2018/19. Although there may be some misclassification of vaccine status due to self- or parent/guardian-reporting, it is unlikely that the increased $\mathrm{A}\left(\mathrm{H}_{1} \mathrm{~N}_{1}\right)$ pdmog detection we observed among unvaccinated children in 2018/19 could be explained by shedding of LAIV virus among those for whom vaccination occurred but was not recognised, recorded or reported.

Our findings only include patients seeking outpatient care; our system cannot assess patterns among inpatients or those not seeking medical attention. Differences in healthcare seeking or testing behaviours by age and/or epidemic may skew surveillance trends based upon case detection alone. To account for possible age-related sampling variation, we assessed trends among influenza test-negative controls identified according to the same study protocol as for cases, recognising, however, that non-influenza causes of ILI may separately vary by age and season. School-aged children 5-19 years old may have higher influenza attack rates $[15,17]$, but their risk of serious outcomes (such as hospitalisation or death) is lower compared with younger paediatric or other age groups [33-36]. Observations driven by serious outcome surveillance may therefore miss the greater involvement of schoolchildren at the community or outpatient levels. Trends we report in the outpatient setting may not be evident in surveillance systems that include a mix of testing indications or healthcare settings, or for which access to diagnostic testing is targeted by age. Nevertheless, the disproportionate involvement of children less than 10 years of age that we highlight was also reported from Australia during its $2018 \mathrm{~A}\left(\mathrm{H}_{1} \mathrm{~N}_{1}\right)$ pdmo9-dominant epidemic [37] and is discernible in other surveillance systems in Canada for the 2018/19 season, including hospitalisation data [1]. Conversely, the lesser involvement of elderly adults during influenza $A\left(\mathrm{H}_{1} \mathrm{~N}_{1}\right)$ pdmo9 vs $A\left(H_{3} \mathrm{~N}_{2}\right)$ seasons is evident in fewer long-term care facility outbreaks to date in 2018/19 compared with $2017 / 18$ or $2016 / 17$ in Canada [38].

Limitations of our study include that we used data available season-to-date for 2018/19 (cases spanning to mid-March 2019) but for other years spanning to end-of-season (late April). The timing, peak and mix of influenza and non-influenza causes of ILI may vary each season and their distribution by age may differ toward seasons' end. This may be especially relevant to the current study given that the involvement of children can be most pronounced during the initial phases of an influenza epidemic [18-20]. However, the seasonal influenza $A\left(\mathrm{H}_{1} \mathrm{~N}_{1}\right)$ pdmog epidemic peak (week 52 2018) has well passed in Canada [1], so that observations summarised about 3 months post-peak (cases spanning to week 11 2019) are likely representative of the $\mathrm{A}\left(\mathrm{H}_{1} \mathrm{~N}_{1}\right)$ pdmog epidemic as a whole. Nevertheless, these analyses should be repeated and assessed elsewhere, including regions that may have a different chronology or relative contribution of seasonal influenza $A\left(\mathrm{H}_{1} \mathrm{~N}_{1}\right)$ pdmog circulation since 2009.

\section{Conclusions}

Children less than 10 years old, notably children aged 5-9 years, contributed more to medically-attended cases of influenza $\mathrm{A}\left(\mathrm{H}_{1} \mathrm{~N}_{1}\right)$ pdmog illness in Canada in 2018/19 compared to prior seasonal influenza epidemics. Age-related differences likely reflect a combination of immuno-epidemiologic and socio-behavioural factors. Over the next decade, children born after 2009 and lacking pandemic-induced immunity to $\mathrm{A}\left(\mathrm{H}_{1} \mathrm{~N}_{1}\right)$ pdmog viruses will be entering the pre-teen and teenage period (10-19 years) associated with the highest social contact rates. The implication for greater transmission during subsequent influenza $A\left(\mathrm{H}_{1} \mathrm{~N}_{1}\right)$ pdmog epidemics warrants ongoing monitoring.

\section{Acknowledgements}

The authors gratefully acknowledge the contribution of sentinel sites whose regular submission of specimens and data provide the basis of our analyses. We wish to acknowledge the administrative, coordination and data entry support in each participating province including: Lisan Kwindt, Kaitlyn Shaw and Shinhye Kim for the British Columbia Centre for Disease Control; Elaine Douglas, Kinza Rizvi, Virginia Goetz, Dylan Kendrick, Manish Ranpara, Yvonne Efegoma and Sarah McDonald for TARRANT in Alberta; Kathleen Parris and Alireza Eshaghi for Public Health Ontario; and Sophie Auger for the Institut national de santé publique du Québec. We thank Catharine Chambers formerly of the British Columbia Centre for Disease Control for her prior contributions to database management. We also thank Yayuk Joffres of the British Columbia Centre for Disease Control for her contribution to the current season's analyses. We acknowledge the laboratory support provided by Rebecca Hickman and Tracy Chan at the British Columbia Centre for Disease Control Public Health Laboratory. We additionally wish to thank those who provided further laboratory and technical support in each province at the British Columbia Centre for Disease Control Public Health Laboratory, the Alberta Provincial Laboratory for Public Health (ProvLab), the Public Health Ontario Laboratory and the Laboratoire de santé publique du Québec (LSPQ). Funding was provided by the British Columbia Centre for Disease Control, Alberta Health and Wellness, Public Health Ontario, Ministère de la santé et des services sociaux du Québec, the Canadian Institutes of Health Research (grant number TPA-90193) and the Public Health Agency of Canada. The views expressed herein do not necessarily represent the view of the Public Health Agency of Canada.

\section{Conflict of interest}

DMS is Principal Investigator on grants received from the Canadian Institutes of Health Research and the Public Health Agency of Canada in support of this work. GDS has received grants for investigator-initiated studies unrelated to influenza vaccine from Pfizer and provided paid expert testimony for the Ontario Nurses Association, the Quebec Ministry of Justice and GSK. JBG has received research grants from Pfizer Inc. to conduct microbiological surveillance of Streptococcus pneumoniae. MK has received research grants from Roche, Siemens and Hologic for unrelated studies. SJD is a 
content expert consultant to Johnson and Johnson (Janssen) Pharmaceuticals on a literature search for point-of-care testing for respiratory viruses. Other authors have no conflicts of interest to declare.

\section{Authors' contributions}

Principal investigators (epidemiological): DMS (national and British Columbia); JAD (Alberta); ALW, MM (Ontario); and GDS (Québec). Principal investigators (laboratory): AJ, MK, MP (British Columbia); MC, SJD (Alberta); JBG (Ontario); HC, CM (Québec); and NB and YL (National Microbiology Laboratory). Additional laboratory and epidemiological support: SM (British Columbia); RO (Ontario). Epidemiological data analysis: SL and DMS. Preparation of first draft: SL and DMS. Draft revision and approval: all authors.

\section{References}

1. Public Health Agency of Canada (PHAC). Weekly influenza reports. Ottawa: PHAC. [Accessed: 22 Mar 2019]. Available from: https://www.canada.ca/en/public-health/services/ diseases/flu-influenza/influenza-surveillance/weekly-reports2018-2019-season.html

2. Centers for Disease Control and Prevention (CDC). FluView: Weekly U.S. influenza surveillance report. Atlanta: CDC. [Accessed: 22 Mar 2019]. Available from: https://www.cdc.gov/ flu/weekly/

3. European Centre for Disease Prevention and Control (ECDC). Flu News Europe: Joint ECDC-WHO/Europe weekly influenza update. Stockholm: ECDC. [Accessed: 22 Mar 2019]. Available from: http://flunewseurope.org

4. Segaloff H, Melidou A, Adlhoch C, Pereyaslov D, Robesyn E, Penttinen P, et al. WHO European Region And The European Influenza Surveillance Network. Co-circulation of influenza $\mathrm{A}\left(\mathrm{H}_{1} \mathrm{~N}_{1}\right)$ pdmog and influenza $\mathrm{A}\left(\mathrm{H}_{3} \mathrm{~N}_{2}\right)$ viruses, World Health Organization (WHO) European Region, October 2018 to February 2019. Euro Surveill. 2019;24(9):1900125. https://doi. org/10.2807/1560-7917.ES.2019.24.9.1900125 PMID: 30862331

5. Skowronski DM, Chambers C, Sabaiduc S, De Serres G, Winter AL, Dickinson JA, et al. Integrated sentinel surveillance linking genetic, antigenic, and epidemiologic monitoring of influenza vaccine-virus relatedness and effectiveness during the 2013-2014 influenza season. J Infect Dis. 2015;212(5):726-39. https://doi.org/10.1093/infdis/jiv177 PMID: 25784728

6. Skowronski DM, Chambers C, Sabaiduc S, De Serres G, Winter AL, Dickinson JA, et al. Beyond antigenic match: possible agent-host and immuno-epidemiological influences on influenza vaccine effectiveness during the 2015-2016 season in Canada. J Infect Dis. 2017;216(12):1487-500. https://doi. org/10.1093/infdis/jix526 PMID: 29029166

7. Skowronski DM, Chambers C, Sabaiduc S, De Serres G, Winter AL, Dickinson JA, et al. A perfect storm: impact of genomic variation and serial vaccination on low influenza vaccine effectiveness during the $2014-2015$ season. Clin Infect Dis. 2016;63(1):21-32. https://doi.org/10.1093/cid/ciw176 PMID: 27025838

8. Skowronski DM, Chambers C, Sabaiduc S, Dickinson JA, Winter AL, De Serres G, et al. Interim estimates of 2016/17 vaccine effectiveness against influenza $A\left(\mathrm{H}_{3} \mathrm{~N}_{2}\right)$, Canada, January 2017. Euro Surveill. 2017;22(6):30460. https://doi. org/10.2807/1560-7917.ES.2017.22.6.30460 PMID: 28205503

9. Skowronski DM, Chambers C, De Serres G, Dickinson JA, Winter A-L, Hickman R, et al. Early season co-circulation of influenza $\mathrm{A}\left(\mathrm{H}_{3} \mathrm{~N}_{2}\right)$ and $\mathrm{B}($ Yamagata): interim estimates of 2017/18 vaccine effectiveness, Canada, January 2018. Euro Surveill. 2018;23(5):18-00035. https://doi.org/10.2807/15607917.ES.2018.23.5.18-00035 PMID: 29409570

10. Skowronski DM, Leir S, Sabaiduc S, Murti M, Dickinson JA, Olsha R, et al. Interim estimates of 2018/19 vaccine effectiveness against influenza $A\left(\mathrm{H}_{1} \mathrm{~N}_{1}\right)$ pdmo9, Canada, January 2019. Euro Surveill. 2019;24(4):1900055. https:// doi.org/10.2807/1560-7917.ES.2019.24.4.1900055 PMID: 30696523

11. Doyle JD, Chung JR, Kim SS, Gaglani M, Raiyani C, Zimmerman RK, et al. Interim estimates of 2018-19 seasonal influenza vaccine effectiveness - United States, February 2019. MMWR Morb Mortal Wkly Rep. 2019;68(6):135-9. https://doi. org/10.15585/mmwr.mm6806a2 PMID: 30763298

12. Kissling E, Rose A, Emborg H-D, Gherasim A, Pebody R, Pozo F, et al. European Ive Group. Interim 2018/19 influenza vaccine effectiveness: six European studies, October 2018 to January 2019. Euro Surveill. 2019;24(8):1900121. https://doi. org/10.2807/1560-7917.ES.2019.24.1900121 PMID: 30808440

13. Chiu SS, Kwan MY, Feng S, Chan EL, Chua H, Wong JS, et al. Early season estimate of influenza vaccination effectiveness against influenza hospitalisation in children, Hong Kong, winter influenza season 2018/19. Euro Surveill. 2019;24(5):1900056. https://doi.org/10.2807/1560-7917. ES.2019.24.5.1900056 PMID: 30722814

14. Statistics Canada. Table 17-10-0005-01: Population estimates on July 1st, by age and sex. Ottawa: Statistics Canada. [Accessed: 8 Feb 2019]. Available from: https://www150. statcan.gc.ca/t1/tbl1/en/tv.action?pid=1710000501

15. Van Kerkhove MD, Hirve S, Koukounari A, Mounts AWH1N1pdm serology working group. Estimating age-specific cumulative incidence for the 2009 influenza pandemic: a meta-analysis of $A\left(\mathrm{H}_{1} \mathrm{~N}_{1}\right)$ pdmog serological studies from 19 countries. Influenza Other Respir Viruses. 2013;7(5):872-86. https://doi. org/10.1111/irv.12074 PMID: 23331969

16. Skowronski DM, Chambers C, Sabaiduc S, Janjua NZ, Li $G$, Petric $M$, et al. Pre- and postpandemic estimates of 2009 pandemic influenza $A\left(\mathrm{H}_{1} \mathrm{~N}_{1}\right)$ seroprotection to inform surveillance-based incidence, by age, during the 2013-2014 epidemic in Canada. J Infect Dis. 2015;211(1):109-14. https:// doi.org/10.1093/infdis/jiu366 PMID: 24973459

17. Somes MP, Turner RM, Dwyer LJ, Newall AT. Estimating the annual attack rate of seasonal influenza among unvaccinated individuals: A systematic review and meta-analysis. Vaccine. 2018;36(23):3199-207. https://doi.org/10.1016/j. vaccine.2018.04.063 PMID: 29716771

18. Mossong J, Hens N, Jit M, Beutels P, Auranen K, Mikolajczyk $R$, et al. Social contacts and mixing patterns relevant to the spread of infectious diseases. PLoS Med. 2008;5(3):e74. https://doi.org/10.1371/journal.pmed.0050074 PMID: 18366252

19. Béraud G, Kazmercziak S, Beutels P, Levy-Bruhl D, Lenne $X$, Mielcarek N, et al. The French connection: the first large population-based contact survey in France relevant for the spread of infectious diseases. PLoS One. 2015;10(7):e0133203. https://doi.org/10.1371/journal.pone.0133203 PMID: 26176549

20. Wallinga J, Teunis $P$, Kretzschmar M. Using data on social contacts to estimate age-specific transmission parameters for respiratory-spread infectious agents. Am J Epidemiol. 2006;164(10):936-44. https://doi.org/10.1093/aje/kwj317 PMID: 16968863

21. Linderman SL, Chambers BS, Zost SJ, Parkhouse K, Li $Y$, Herrmann C, et al. Potential antigenic explanation for atypical $\mathrm{H}_{1} \mathrm{~N}_{1}$ infections among middle-aged adults during the 2013-2014 influenza season. Proc Natl Acad Sci USA. 2014;111(44):15798-803. https://doi.org/10.1073/ pnas.1409171111 PMID: 25331901

22. Morens DM, Burke DS, Halstead SB. The wages of original antigenic sin. Emerg Infect Dis. 2010;16(6):1023-4. https://doi. org/10.3201/eid1606.100453 PMID: 20507764

23. Skowronski DM, Hottes TS, McElhaney JE, Janjua NZ, Sabaiduc $\mathrm{S}$, Chan T, et al. Immuno-epidemiologic correlates of pandemic H1N1 surveillance observations: higher antibody and lower cell-mediated immune responses with advanced age. I Infect Dis. 2011;203(2):158-67. https://doi.org/10.1093/infdis/jiq039 PMID: 21288814

24. Thompson WW, Shay DK, Weintraub E, Brammer L, Cox $\mathrm{N}$, Anderson LJ, et al. Mortality associated with influenza and respiratory syncytial virus in the United States. JAMA. 2003;289(2):179-86. https://doi.org/10.1001/jama.289.2.179 PMID: 12517228

25. Thompson MG, Shay DK, Zhou H, Bridges CB, Cheng PY, Burns $E$, et al. Centers for Disease Control and Prevention (CDC). Estimates of deaths associated with seasonal influenza -.- United States, 1976-2007. MMWR Morb Mortal Wkly Rep. 2010;59(33):1057-62. PMID: 20798667

26. Ng S, Lopez R, Kuan G, Gresh L, Balmaseda A, Harris E, et al. The Timeline of Influenza Virus Shedding in Children and Adults in a Household Transmission Study of Influenza in Managua, Nicaragua. Pediatr Infect Dis J. 2016;35(5):5836. https://doi.org/10.1097/INF.0000000000001083 PMID: 26910589

27. Wang B, Russell ML, Fonseca K, Earn DJD, Horsman G, Van Caeseele $\mathrm{P}$, et al. Predictors of influenza a molecular viral shedding in Hutterite communities. Influenza Other Respir Viruses. 2017;11(3):254-62. https://doi.org/10.1111/irv.12448 PMID: 28207989

28. Belongia EA, Simpson MD, King JP, Sundaram ME, Kelley NS, Osterholm MT, et al. Variable influenza vaccine effectiveness by subtype: a systematic review and meta-analysis of testnegative design studies. Lancet Infect Dis. 2016;16(8):942-51. 
https://doi.org/10.1016/S1473-3099(16)00129-8 PMID: 27061888

29. Statistics Canada. Table 13-10-0096-25 Influenza immunization in the past 12 months, by age group. Ottawa: Statistics

Canada. [Accessed: 3 Mar 2019]. Available: https://www150. statcan.gc.ca/t1/tbl1/en/tv.action?pid=1310009625

30. Grohskopf LA, Sokolow LZ, Broder KR, Olsen SJ, Karron RA, Jernigan DB, et al. Prevention and control of seasonal influenza with vaccines: recommendations of the Advisory Committee on Immunization Practices-United States, 2016-17 influenza season. MMWR Recomm Rep. 2016;65(5):1-54.

31. Grohskopf LA, Sokolow LZ, Broder KR, Walter EB, Bresee JS, Fry AM, et al. Prevention and control of seasonal influenza with vaccines: recommendations of the Advisory Committee on Immunization Practices-United States, 2017-18 influenza season. MMWR Recomm Rep. 2017;66(2):1-20.

32. Public Health Agency of Canada (PHAC). Addendum - LAIV use in children and adolescents. Advisory Committee Statement (ACS). National Advisory Committee on Immunization (NACI). Canadian Immunization Guide Chapter on Influenza and Statement on Seasonal Influenza Vaccine for 2016-2017. Ottawa: PHAC. [Accessed: 24 Feb 2019]. Available from: https://www.canada.ca/content/dam/phac-aspc/migration/ phac-aspc/naci-ccni/assets/pdf/addendum-2016-2017-laiv-veeng.pdf

33. Monto AS, Sullivan KM. Acute respiratory illness in the community. Frequency of illness and the agents involved. Epidemiol Infect. 1993;110(1):145-6o. https://doi.org/10.1017/ So950268800050779 PMID: 8432318

34. Shang M, Blanton L, Brammer L, Olsen SJ, Fry AM. Influenzaassociated pediatric deaths in the United States, 2010-2016. Pediatrics. 2018;141(4):e20172918. https://doi.org/10.1542/ peds.2017-2918 PMID: 29440502

35. Donaldson LJ, Rutter PD, Ellis BM, Greaves FE, Mytton OT, Pebody RG, et al. Mortality from pandemic A/H1N1 2009 influenza in England: public health surveillance study. BMJ. 2009;339:b5213.

36. Kostova D, Reed C, Finelli L, Cheng P-Y, Gargiullo PM, Shay DK, et al. Influenza illness and hospitalizations averted by influenza vaccination in the United States, 2005-2011. PLoS One. 2013;8(6):e66312. https://doi.org/10.1371/journal. pone.0066312 PMID: 23840439

37. Australian Government. 2018 Influenza Season in Australia: A summary from the National Influenza Surveillance Committee. Information Brief (updated on 16 November 2018). Canberra: Department of Health, Australian Government; 2018. Available from: http://www.health.gov.au/internet/main/publishing. nsf/Content/cda-surveil-ozflu-flucurr.htm/\$File/2018-SeasonSummary.pdf

38. BC Centre for Disease Control. Influenza surveillance reports 2018-19 season. Vancouver: Provincial Health Services Authority. [Accessed: 22 Mar 2019]. Available from: http://www.bccdc.ca/health-professionals/data-reports/ communicable-diseases/influenza-surveillance-reports

\section{License, supplementary material and copyright}

This is an open-access article distributed under the terms of the Creative Commons Attribution (CC BY 4.0) Licence. You may share and adapt the material, but must give appropriate credit to the source, provide a link to the licence and indicate if changes were made.

Any supplementary material referenced in the article can be found in the online version.

This article is copyright of the authors or their affiliated institutions, 2019. 